\title{
Erratum zu: Innovationsmanagement der chemischen Industrie im digitalen Zeitalter
}

Sabine Landwehr-Zloch und Josef Glaß

\section{Erratum zu: S. Landwehr-Zloch und J. Glaß (Hrsg.), Innovationsmanagement der chemischen Industrie im digitalen Zeitalter, https://doi.org/10.1007/978-3-662-61358-0}

Trotz sorgfältiger Erstellung unserer Bücher lassen sich Fehler nicht vermeiden, daher weisen wir auf Folgendes hin:

Die Originalversionen des Vorworts und Kapitels 7 wurden revidiert.

Die Firmenbezeichnung im Vorwort auf S. VIII muss korrekt heißen: Die Beiträge kommen von Unternehmensvertretern der Firmen Henkel und Budenheim. Im Kap. 10.1007/978-3-662-61358-0_7 auf S. 117 fehlt die Firmenzugehörigkeit von Herrn Rath: Hier muss es heißen: Chemische Fabrik Budenheim KG.

Die korrigierte Version des Kapitels ist verfügbar unter 10.1007/978-3-662-61358-0 